\title{
BMJ Open The effect of lowering the legal blood alcohol concentration limit on driving under the influence (DUI) in southern Taiwan: a cross-sectional retrospective analysis
}

\author{
Yu-Chin Tsai, ${ }^{1}$ Shao-Chun Wu, ${ }^{2}$ Jin-Fu Huang, ${ }^{1}$ Spencer $\mathrm{C} \mathrm{H} \mathrm{Kuo,}{ }^{3}$ \\ Cheng-Shyuan Rau, ${ }^{1}$ Peng-Chen Chien, ${ }^{3}$ Hsiao-Yun Hsieh, ${ }^{3}$ Ching-Hua Hsieh ${ }^{3}$
}

To cite: Tsai Y-C, Wu S-C, Huang J-F, et al. The effect of lowering the legal blood alcohol concentration limit on driving under the influence (DUI) in southern Taiwan: a cross-sectional retrospective analysis. BMJ Open 2019;9:e026481. doi:10.1136/ bmjopen-2018-026481

- Prepublication history for this paper is available online. To view these files, please visit the journal online (http://dx.doi org/10.1136/bmjopen-2018026481).

Y-CT and S-CW contributed equally.

Received 7 September 2018 Revised 18 February 2019 Accepted 21 February 2019

Check for updates

(C) Author(s) (or their employer(s)) 2019. Re-use permitted under CC BY-NC. No commercial re-use. See rights and permissions. Published by BMJ.

For numbered affiliations see end of article.

Correspondence to Dr Ching-Hua Hsieh; m93chinghua@gmail.com

\section{ABSTRACT}

Objectives We aimed to profile the epidemiological changes of driving under the influence (DUI) in southern Taiwan after the legal blood alcohol concentration (BAC) limit was lowered from 50 to $30 \mathrm{mg} / \mathrm{dL}$ in 2013 .

Setting Level 1 trauma medical centre in southern Taiwan.

Participants Data from 7447 patients (4375 males and 3072 females) were retrieved from the trauma registry system of a single trauma centre to examine patient characteristics (gender, age and BAC), clinical outcome variables (Abbreviated Injury Score, Injury Severity Score and mortality) and vehicular crash-related factors (vehicle type, airbag use in car crashes, helmet use in motorcycle crashes and time of crash) before and after the BAC limit change.

Results Our results indicated that the percentage of DUl patients significantly declined from $10.99 \%(n=373)$ to $6.64 \%(n=269)$ after the BAC limit was lowered. Airbag use in car crashes (OR: $0.30,95 \% \mathrm{Cl} 0.10$ to $0.88, p=0.007$ ) and helmet use in motorcycle crashes (OR: $0.20,95 \% \mathrm{Cl} 0.15$ to $0.26, p<0.001$ ) was lower in DUI patients compared with non-DUI patients after the BAC limit change, with significant negative correlation. DUI behaviour increased crash mortality risk before the BAC limit change (OR: $4.33,95 \% \mathrm{Cl} 2.20$ to 8.54 ), and even more so after (OR: $5.60,95 \% \mathrm{Cl} 3.16$ to 9.93 ). The difference in ORs for mortality before and after the change in the BAC legal limit was not significant $(p=0.568)$.

Conclusion This study revealed that lowering the BAC limit to $30 \mathrm{mg} / \mathrm{dL}$ significantly reduced the number of DUI events, but failed to result in a significant reduction in mortality in these trauma patients.

\section{INTRODUCTION}

According to the WHO, over 1.2 million people die each year in road traffic crashes, with $75 \%$ of the fatalities occurring in men in the economically active age range. ${ }^{1}$ It is estimated that over $90 \%$ of road traffic deaths occur in low-income and middle-income countries, causing significant gross

\section{Strengths and limitations of this study}

- The data were retrieved from the registered trauma database in which data were prospectively collected with internal validation.

- This study compared the same span of time before and after blood alcohol concentration limit change.

- This study was limited by its retrospective design.

- Some confounders like baseline characteristics, the use of psychoactive medication and the exact time elapsed from injury to an alcohol test may lead to a bias in assessment.

- Data from one trauma centre may not indicate the observed effect could be generalised to other regions or countries.

domestic product (GDP) losses of up to $5 \% .^{2}$ Driving under the influence (DUI) of alcohol increases the risk of crash as well as the severity of crash-related injuries, and results in longer hospital stays, higher healthcare costs and poorer outcomes compared with drivers in non-DUI-related crashes. $^{3-6}$ In particular, when the driver's blood alcohol concentration (BAC) exceeds $50 \mathrm{mg} / \mathrm{dL}$, the risk and severity of traffic crashes increase remarkably. ${ }^{7-10}$ Efforts to reduce alcohol-impaired driving have included implementing laws regarding minimum legal drinking age and BAC limit when driving, taxation of alcohol, providing alcohol education and establishing alcohol treatment programmes. ${ }^{11}$

Over the past decade (2007-2016), DUI-related traffic crashes have caused over 3000 deaths and 110000 injuries in Taiwan. ${ }^{12}$ Nevertheless, prior to April 1999, DUI was not deemed a serious crime in Taiwan: it was legal to drive with BAC of $50 \mathrm{mg} / \mathrm{dL}$; drivers with BAC between 50 and $110 \mathrm{mg} / \mathrm{dL}$ violated Road Traffic Security Rules and faced license 
suspension or revocation, or a financial penalty; drivers with $\mathrm{BAC}>110 \mathrm{mg} / \mathrm{dL}$ violated Article 185 of the Criminal Law, but would only face imprisonment of less than a year and fines of $<30,000$ New Taiwan Dollars (NTD) ( US\$1000). In more recent years, DUI has received increased media attention, as alcohol-impaired traffic crashes are frequently reported. A series of amendments were made to the Road Traffic Management and Penalty Act, Road Traffic Security Rules and Article 185 of the Criminal Law, ${ }^{13}$ including the most recent amendment to Road Traffic Security Rules in 2013, which lowered the legal BAC limit from 50 to $30 \mathrm{mg} / \mathrm{dL}$. In addition, financial penalties were increased by up to $50 \%$. According to national statistics, alcohol-impaired driving casualties reduced after these regulation and law changes. ${ }^{13}$ However, data on monthly injuries and deaths resulting from DUI-related crashes and number of monthly DUI violations are obtained from sobriety checkpoints by the police, and specific data regarding the impact of DUI on medical service utilisation after change in the legal BAC limit are not available. Therefore, we aimed to compare the epidemiological profile of DUI in southern Taiwan before and after the 2013 change in legal BAC limit using data from the trauma registry system. We examined patient demographics and outcomes, DUI status, crash-related factors, as well as outcomes before and after the limit change to define the prognosis and risk factors for DUI-related injury and mortality, and assess the effect of BAC limit change on these factors.

\section{PATIENTS AND METHODS}

\section{Patient and public involvement}

The patients and the public were not involved in this study.

We retrospectively collected patient data from the trauma registry system of the Kaohsiung Chang Gung Memorial Hospital, a 2686-bed Level I regional trauma centre that provides emergent care to trauma patients primarily from southern Taiwan. ${ }^{14} 15$ Only drivers in car and motorcycle crashes that occurred in the Kaohsiung and Pingtung areas of Taiwan who were hospitalised between July 2009 and December 2016 were included. Twenty-three patients with incomplete data were excluded, as well as those whose hospital visit took place between January 2013 and June 2013, the period when amendments to the Road Traffic Management and Penalty Act were announced and implemented. Data from 7447 patients were used for the analysis.

BAC tests were routinely ordered for patients in the emergency room (ER) with clinical suspicion of DUI. Patients with BAC $>30 \mathrm{mg} / \mathrm{dL}$ (the threshold for DUI after January 2013) were categorised into two groups according to when their visit took place: before BAC limit change (July 2009 to December 2012; n=3395 patients) and after BAC limit change (July 2013 to December 2016; $\mathrm{n}=4052$ patients). Detailed patient information was recorded and included the following variables: age, gender, type of vehicle crash, time and location of crash, airbag use (car crashes only), helmet use (motorcycle crashes only), BAC, hospital length of stay (LOS), in-hospital mortality and crash-related trauma by body region. The Abbreviated Injury Score (AIS) was used to evaluate injury severity in the following regions: head/neck, face, chest, abdomen, extremities (including pelvis) and external. Patients with higher AIS were combined for analysis in some regional subgroups due to inadequate patient numbers. The Injury Severity Score (ISS) was calculated by summing the square of the three highest AIS scores in each region. ${ }^{16}$

Patient characteristics, clinical outcome variables and vehicular crash-related factors were compared before and after the BAC limit change using the chi-square test, Student's t-test and Mann-Whiney U-test. Differences in characteristics between patients in DUI (BAC $\geq 30 \mathrm{mg}$ / $\mathrm{dL}$ ) and non-DUI groups were also examined. Parameters were presented as numbers (percentage), median \pm $\mathrm{IQR}$ range or mean $\pm \mathrm{SD}$. Logistic regression was used to define changes in baseline traits and clinical outcomes in the DUI and non-DUI groups before and after the BAC limit change. Breslow-Day statistics testing was performed to examine homogeneity in different stratifications. We also analysed the ratio of single-vehicle nighttime (SVN) crashes to multiple-vehicle daytime (MVD) crashes as a proxy measure used in many studies for alcohol involvement. ${ }^{17} 18$ R Statistical SoftwareV.3.3.3 was used to geographically present the change in DUI event density in southern Taiwan, and demonstrate the monthly trend in the number of DUI patients from 2009 to 2016. All other analyses were performed using SAS V.9.4. Statistical significance was defined as $\mathrm{p}<0.05$.

\section{RESULTS}

The average age at the time of crash was $43.68 \pm 18.70$ (range: 11-90 years). Of these patients, 642 (8.6\%) were classified as DUI $(\mathrm{BAC} \geq 30 \mathrm{mg} / \mathrm{dL})$. Most crashes were with a motorcycle vehicle (7237 patients; $97.2 \%)$, and occurred between 06:00 and 14:00 (3173 patients; $42.6 \%)$. Motorcyclists were wearing a helmet at the time of the crash in $88.93 \%(\mathrm{n}=7237)$ of the patients, whereas $63.81 \%(\mathrm{n}=134)$ of car drivers had airbag protection. The average mortality was $1.34 \%$, and median hospital LOS was 6 days.

As shown in table 1, 3395 patients were admitted to our hospital before the BAC limit change, and 4052 patients after. In both time periods, patients tended to be males between the ages of 40 and 45 . The percentage of DUI patients significantly declined from $10.99 \%(\mathrm{n}=373)$ to $6.64 \%(\mathrm{n}=269)$ after the BAC limit change (figure 1), and the average BAC at admission decreased from 21.19 to $12.31 \mathrm{mg} / \mathrm{dL}$. This trend was observed across different regions in southern Taiwan, as shown in figure 2. The percentage of airbag use in car crashes decreased, while helmet use in motorcycle crashes increased. No significant changes in mortality and hospital stay were found in 
Table 1 Patient characteristics, clinical variables and vehicular crash-related variables before and after BAC limit change

\begin{tabular}{|c|c|c|c|}
\hline & Before BAC limit change & After BAC limit change & $P$ value \\
\hline Gender, n (\%) & & & 0.028 \\
\hline Male & $2041(60.12)$ & $2334(57.6)$ & \\
\hline Age (years) & 42.77 (18.34) & $44.45(18.97)$ & $<0.001^{*}$ \\
\hline DUI, n (\%) & & & $<0.001$ \\
\hline No & $3022(89.01)$ & 3783 (93.36) & \\
\hline $\mathrm{BAC}(\mathrm{mg} / \mathrm{dL})$ & $21.19(62.49)$ & $12.31(47.12)$ & $<0.001^{*}$ \\
\hline Car, n (\%) & & & 0.057 \\
\hline Airbag & $73(70.19)$ & $61(57.55)$ & \\
\hline No airbag & $31(29.81)$ & $45(42.45)$ & \\
\hline ISS & $9(9)$ & $9(9)$ & $0.041^{*}$ \\
\hline Hospital stay (days) & $6(7)$ & $7(8)$ & $0.198^{*}$ \\
\hline Mortality, n (\%) & & & 0.125 \\
\hline Alive & 3357 (98.88) & $3990(98.47)$ & \\
\hline Death & $38(1.12)$ & $62(1.53)$ & \\
\hline Seasons, n (\%) & & & $<0.001$ \\
\hline Spring & $605(17.82)$ & $994(24.53)$ & \\
\hline Summer & $874(25.74)$ & $1008(24.88)$ & \\
\hline Weekdays, n (\%) & & & 0.012 \\
\hline Monday & $487(14.34)$ & $639(15.77)$ & \\
\hline Tuesday & $553(16.29)$ & $558(13.77)$ & \\
\hline Wednesday & $440(12.96)$ & $587(14.49)$ & \\
\hline Thursday & $494(14.55)$ & $590(14.56)$ & \\
\hline Friday & $480(14.14)$ & $613(15.13)$ & \\
\hline Saturday & $504(14.85)$ & $582(14.36)$ & \\
\hline Sunday & 437 (12.87) & $483(11.92)$ & \\
\hline
\end{tabular}

*Mann-Whitney test.

BAC, blood alcohol concentration; DUI, driving under the influence; ISS, Injury Severity Score.

our analyses. Patient numbers did not vary by season or day of the week, although a slight decrease was observed in the spring before the BAC limit change.

Examination of patient characteristics, crash-related factors and clinical outcomes in DUI and non-DUI patients revealed that patients in the DUI group were mostly male $(88.47 \%)$ compared with the non-DUI group $(55.94 \%)$ (table 2). Patients in the DUI group were significantly younger $(p<0.001)$. Reduced use of airbags in car crashes and helmets in motorcycle crashes were found in higher proportion in the DUI group than in the non-DUI group. DUI patients tended to have significantly higher ISS (13 vs 9 , $\mathrm{p}<0.001$ ) and longer hospital stay ( 8 vs 6 days, $\mathrm{p}<0.001$ ) than non-DUI patients. A significantly higher mortality rate was found in DUI patients than in non-DUI $(4.67 \%$ vs $1.03 \%, \mathrm{p}<0.001)$. No significant seasonal differences 
20 .
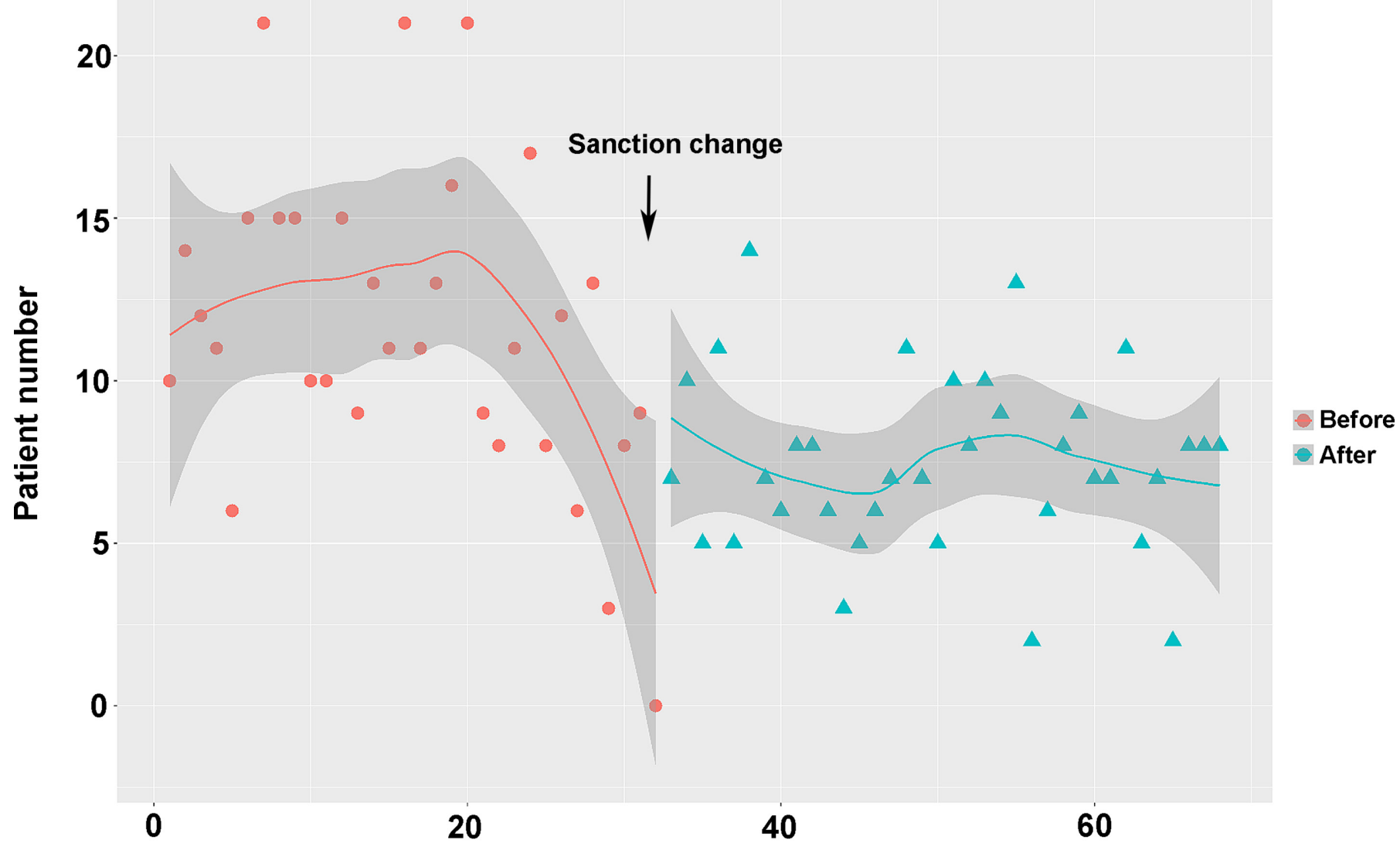

\section{Time progress (months)}

Figure 1 Monthly number of DUI (BAC $\geq 30 \mathrm{mg} / \mathrm{dL}$ ) patients before and after BAC limit change. BAC, blood alcohol concentration; DUI, driving under the influence.

were found between the groups. Time of visit to the ER differed for the DUI patients compared with the non-DUI patients. Most DUI patients visited the ER between 22:00 and 06:00 $(50.31 \%)$, while only $13.33 \%$ of non-DUI patients visited at this time. Additionally, DUI crashes tended to occur on weekends $(18.69 \%$ on Saturday and $19.31 \%$ on Sunday).

Table 3 compares OR for different stratified parameters before and after the BAC limit change. Males still showed increased odds of DUI (crude OR: $6.01,95 \%$ CI 4.69 to 7.69), but the BAC limit change showed no significant effect on DUI behaviour between genders. DUI behaviour increased the crash mortality risk before the BAC limit change (OR: 4.33, 95\% CI 2.20 to 8.54), and even more so after (OR: $5.60,95 \%$ CI 3.16 to 9.93 ). The difference in these ORs was not significant $(\mathrm{p}=0.568)$. Regarding time of crash, a greater number of DUI patients appeared between 22:00 and 06:00 (OR 12.70) than between 14:00 and 22:00 (3.04) and between 06:00 and 14:00 (baseline). This trend was significantly increased after the BAC limit change, which showed ORs of 20.76 and 5.50, respectively. There was no significant correlation between airbag use and DUI behaviour in car crashes (OR 0.49, 95\% CI 0.20 to 1.18) before the change in BAC limit. However, car crashes with airbag use were less frequent in DUI patients than in non-DUI patients after the BAC limit change
(OR: $0.30,95 \%$ CI 0.10 to 0.88 ), with a significantly negative correlation. Similar results were found in motorcycle crashes. Helmet use in motorcycle crashes was a protective factor with a negative correlation to DUI behaviour. This negative correlation was reinforced by the change in BAC limit. The OR of helmet use and DUI was 0.42 (95\% CI 0.32 to 0.55 ) before the change and $0.30(95 \%$ CI 0.15 to 0.26 ) after, with significant difference between them $(\mathrm{p}<0.001)$. Season of crash had no effect on DUI behaviour either before or after the BAC limit change. Workdays were significantly negatively correlated with DUI behaviour as compared with weekends (Saturday and Sunday) both before and after BAC limit change. In addition, the SVN/MVD ratio significantly dropped to 0.48 from 0.60 after the change in BAC limit was implemented, indicating that the change had the effect of reducing DUI behaviour.

The AIS of different regions were examined in DUI and non-DUI patients, and indicated that DUI patients were more likely to sustain injuries to the head and neck, face, thorax and abdomen than non-DUI patients (table 4). No significant difference was found in external injuries between DUI and non-DUI patients. However, patients with DUI were less likely than non-DUI patients to suffer from severe injury to the extremities. 


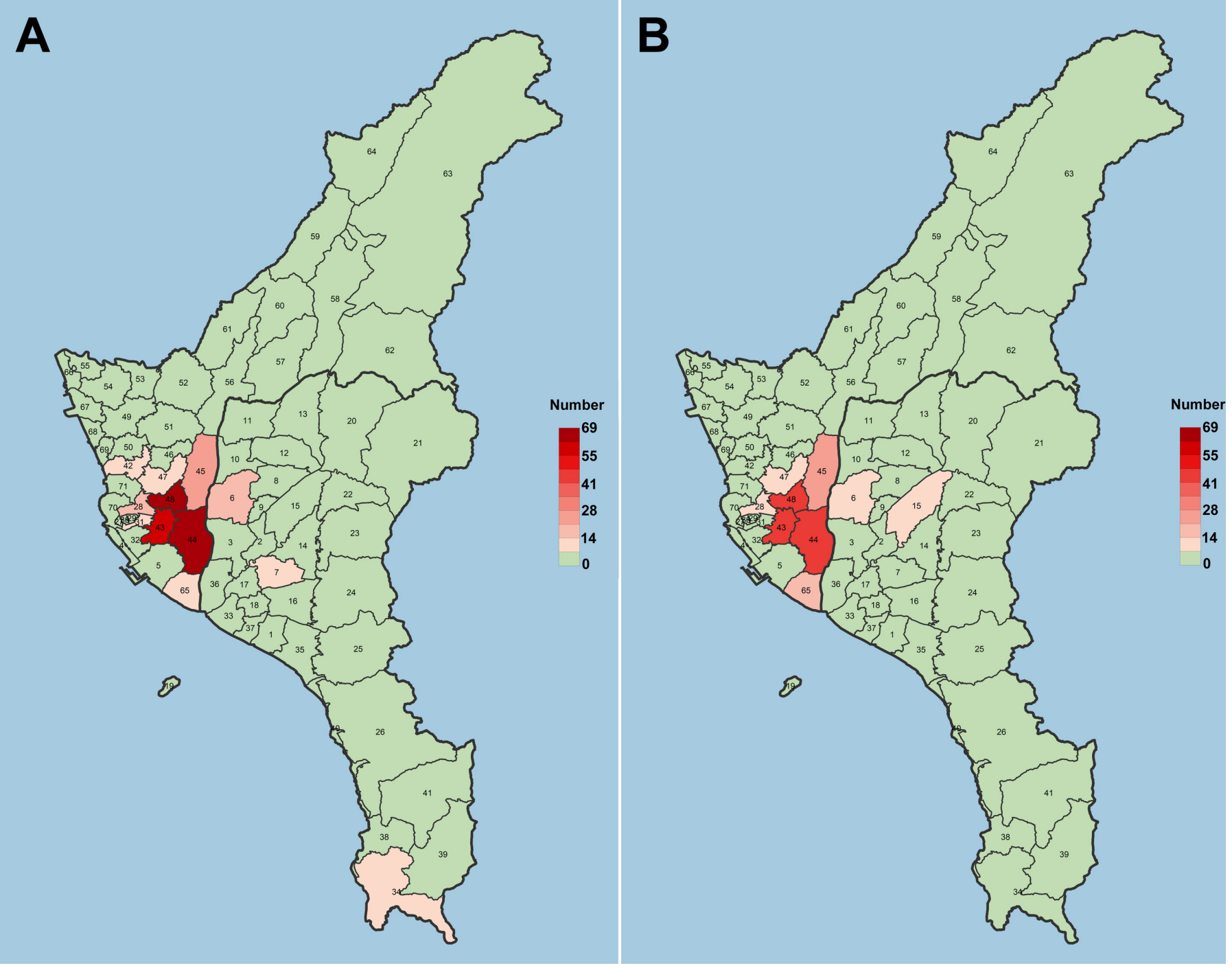

Figure 2 DUI (BAC $\geq 30 \mathrm{mg} / \mathrm{dL}$ ) event density over the 71 district areas of southern Taiwan (A, before BAC limit change; $B$, after BAC limit change). BAC, blood alcohol concentration; DUI, driving under the influence.

\section{DISCUSSION}

Our analyses presented various factors associated with DUI behaviour, including gender, mortality, time of day and day of week of the crash, use of airbags in cars and use of helmets in motorcyclists. In this study, females accounted for a minor proportion (12\%) of DUI patients, consistent with previous research. ${ }^{19}$ Complex causal relationships in physiological and social factors may account for the difference in males and females involved in DUI. Our previous studies also reported more males than females with vehicular crashes sent to our ER. ${ }^{14}{ }^{20}$ Compared with females, males had a higher risk of motorcycle crashes, ${ }^{21}{ }^{22}$ which accounted for $\sim 60 \%$ of injuries in southern Taiwan. ${ }^{14} 20$ Male/female differences in alcoholic liver injury, ${ }^{23}$ alcohol-induced brain injury ${ }^{24}$ and alcohol-related behavioural and medical problems have also been reported. ${ }^{25-27}$ Increased vehicle performance and a higher number of safety features lead to greater risk-taking behaviour by the driver, ${ }^{28}$ and our results indicated that drivers using airbags in their vehicles show a significantly lower OR of being in a DUI crash. Although the decreased use of airbags may be due to the fact that DUI drivers tend to drive older vehicles, not wear a safety belt and drive over the speed limit, this finding could indicate a relationship between the value placed on safety (eg, purchase cars with more safety features) and the avoidance of risk-taking behaviours such as DUI. Our study also examined helmet use in motorcyclists, which has been mandatory for motorcyclists in Taiwan since June 1997; helmets were used by $90 \%$ of patients driving a motorcycle in this study. Previous studies have reported helmet use to be a protective factor or strong predictor of motorcycle crashes. ${ }^{21}{ }^{29-31}$ Our study also found that helmet use plays a significantly protective role in DUI crashes, supporting findings from Ohio, USA and Iran that suggest that motorcyclists involved in alcohol-involved crashes are significantly less likely to wear a helmet. ${ }^{32}{ }^{33}$ The decreased helmet use rate in our data may have contributed to the higher mortality that we saw in DUI motorcycle drivers after the legal BAC limit was lowered to $30 \mathrm{mg} / \mathrm{dL}$. 
Table 2 Patient characteristics, clinical variables and crash-related variables in DUI (BAC $\geq 30 \mathrm{mg} / \mathrm{dL}$ ) and non-DUI patients

\begin{tabular}{|c|c|c|c|}
\hline & DUI & Non-DUI & $P$ value \\
\hline Gender, n (\%) & & & $<0.001$ \\
\hline Male & $568(88.47)$ & $3807(55.94)$ & \\
\hline Female & $74(11.53)$ & $2998(44.06)$ & \\
\hline Age (years) & $39.64(12.76)$ & $44.07(19.13)$ & $<0.001^{*}$ \\
\hline Car, n (\%) & & & 0.020 \\
\hline Airbag & $25(50.00)$ & $109(68.13)$ & \\
\hline No airbag & $25(50.00)$ & $51(31.88)$ & \\
\hline Motorcycle, n (\%) & & & $<0.001$ \\
\hline Helmet & $433(73.14)$ & $6003(90.34)$ & \\
\hline No helmet & $159(26.86)$ & $642(9.66)$ & \\
\hline ISS & $13(14)$ & $9(7)$ & $<0.001^{*}$ \\
\hline Hospital stay (days) & $8(11)$ & $6(7)$ & $<0.001^{*}$ \\
\hline Mortality, n (\%) & & & $<0.001$ \\
\hline Alive & $612(95.33)$ & $6735(98.97)$ & \\
\hline Death & $30(4.67)$ & $70(1.03)$ & \\
\hline Seasons, n (\%) & & & 0.522 \\
\hline Spring & $135(21.03)$ & $1464(21.51)$ & \\
\hline Summer & $153(23.83)$ & $1729(25.41)$ & \\
\hline Autumn & $163(25.39)$ & $1769(26.00)$ & \\
\hline Winter & $191(29.75)$ & $1843(27.08)$ & \\
\hline Time, n (\%) & & & $<0.001$ \\
\hline 06:00-14:00 & $70(10.90)$ & $3103(45.60)$ & \\
\hline 14:00-22:00 & 249 (38.79) & $2795(41.07)$ & \\
\hline 22:00-06:00 & $323(50.31)$ & 907 (13.33) & \\
\hline Weekdays, n (\%) & & & $<0.001$ \\
\hline Monday & $81(12.62)$ & $1045(15.36)$ & \\
\hline Tuesday & $72(11.21)$ & $1039(15.27)$ & \\
\hline Wednesday & $85(13.24)$ & $942(13.84)$ & \\
\hline Thursday & 79 (12.31) & $1005(14.77)$ & \\
\hline Friday & $81(12.62)$ & $1012(14.87)$ & \\
\hline Saturday & $120(18.69)$ & $966(14.20)$ & \\
\hline Sunday & $124(19.31)$ & $796(11.70)$ & \\
\hline
\end{tabular}

*Mann-Whitney test.

BAC, blood alcohol concentration; DUI, driving under the influence; ISS, Injury Severity Score.

Our analysis is consistent with findings in Taiwan based on national statistics ${ }^{13}$ that report a significant reduction in DUI events after the BAC limit change. Previous studies report reductions in both crashes and fatalities when legal limits for BAC are lowered to $50 \mathrm{mg} / \mathrm{dL}{ }^{34} 35$ A significant decrease of $3.7 \%$ (95\% CI $0.9 \%$ to $6.5 \%)$ in fatally injured drivers with a BAC level equal to or $>50 \mathrm{mg} / \mathrm{dL}$ was found following the change. ${ }^{36} \mathrm{~A}$ recent meta-analysis examined the impact of lowering the legal BAC limit to $50 \mathrm{mg} / \mathrm{dL}$, and found an $11.1 \%$ decrease in rates of fatal alcohol-related crashes. ${ }^{37}$ In this study, the proportion of male and female DUI patients and overall mortality rate did not change after the legal limit change.
However, while the proportion of males and females did not change, other elements in patient characteristics changed in our study after the legal BAC was lowered to $30 \mathrm{mg} / \mathrm{dL}$ : the percentage of DUI patients significantly decreased from $10.99 \%$ to $6.6 \%$ and average BAC at admission decreased from 21.19 to $12.31 \mathrm{mg} / \mathrm{dL}$. The decline in DUI events can be seen in the different geographical regions of Kaohsiung and Pingtung surrounding our hospital. Time of injury appears to play a role in severity of injury. It has been reported that drivers not under the influence of alcohol suffer more severe injuries between midnight and early morning compared with early nighttime. ${ }^{38}$ Findings from other studies have indicated that 


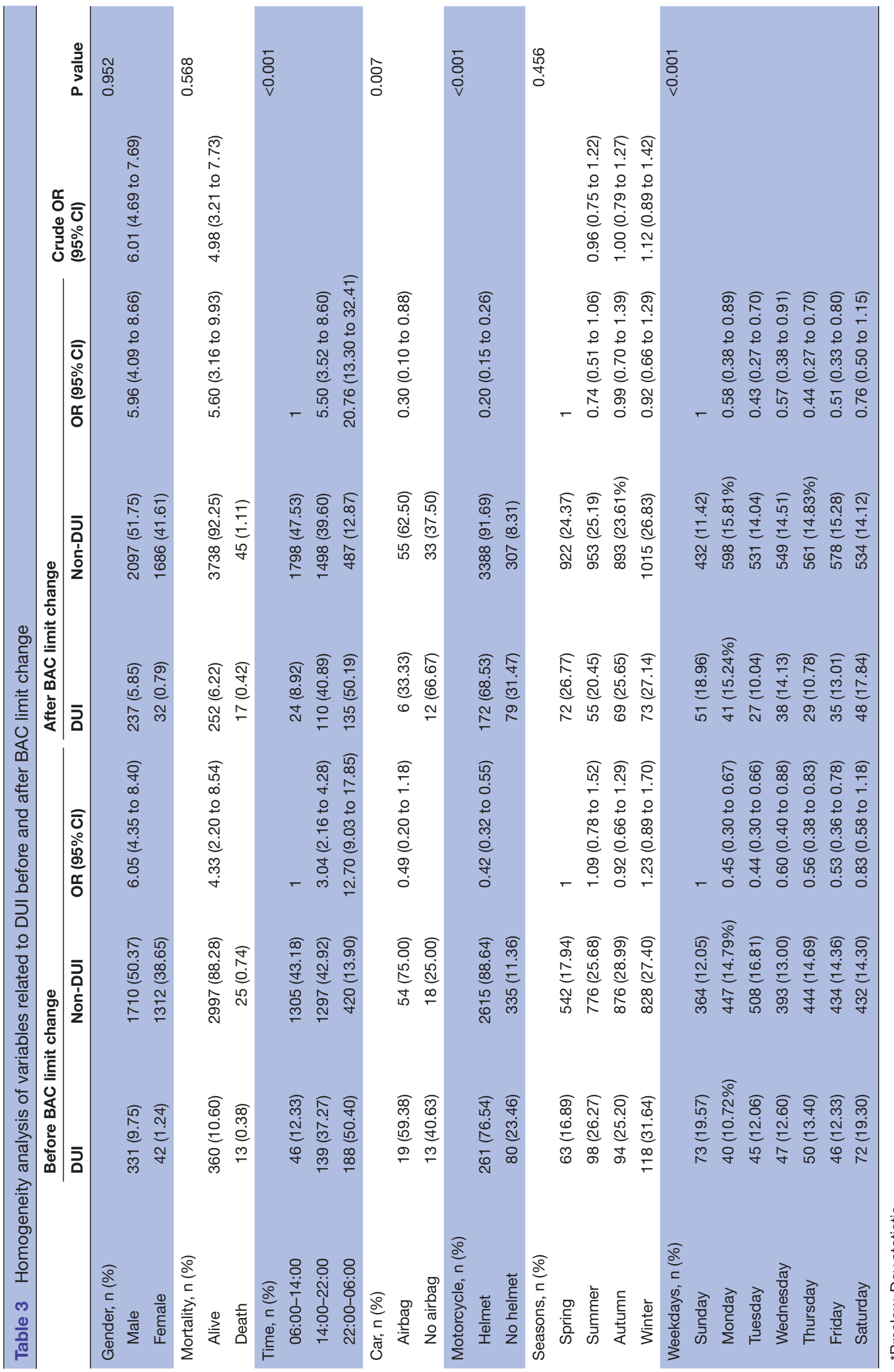


Table 4 The distribution of Abbreviated Injury Scale score by region in DUI (BAC $\geq 30 \mathrm{mg} / \mathrm{dL}$ ) and non-DUI patients

\begin{tabular}{|c|c|c|c|c|}
\hline & DUI & Non-DUI & OR $(95 \% \mathrm{Cl})$ & $P$ value \\
\hline Head/neck & & & & $<0.0001$ \\
\hline 0 & 269 (41.90\%) & 4799 (70.52\%) & 1 & \\
\hline 1 & $94(14.64 \%)$ & $638(9.38 \%)$ & 2.63 (2.05 to 3.37 ) & \\
\hline 2 & $22(3.43 \%)$ & 105 (1.54\%) & 3.74 (2.32 to 6.02$)$ & \\
\hline 3 & $81(12.62 \%)$ & 506 (7.44\%) & 2.86 (2.19 to 3.72$)$ & \\
\hline 4 & $131(20.40 \%)$ & 597 (8.77\%) & 3.92 (3.12 to 4.91$)$ & \\
\hline $5-6$ & $45(7.01 \%)$ & $1160(2.35 \%)$ & 0.69 (0.50 to 0.96$)$ & \\
\hline Face & & & & $<0.0001$ \\
\hline 0 & 361 (56.23\%) & $5342(78.50 \%)$ & 1 & \\
\hline 1 & $64(9.97 \%)$ & $493(7.24 \%)$ & 1.921 (1.45 to 2.55$)$ & \\
\hline 2 & 215 (33.49\%) & 949 (13.95\%) & 3.353 (2.79 to 4.02 ) & \\
\hline 3 & $2(0.31 \%)$ & $21(0.31 \%)$ & 1.409 (0.33 to 6.03$)$ & \\
\hline Thorax & & & & $<0.0001$ \\
\hline 0 & $488(76.01 \%)$ & $5640(82.88 \%)$ & 1 & \\
\hline 1 & $31(4.83 \%)$ & $220(3.23 \%)$ & 1.63 (1.11 to 2.40$)$ & \\
\hline 2 & $27(4.21 \%)$ & $306(4.50 \%)$ & $1.02(0.681$ to 1.53$)$ & \\
\hline 3 & $57(8.88 \%)$ & $437(6.42 \%)$ & 1.51 (1.13 to 2.02$)$ & \\
\hline 4 & 37 (5.76\%) & $196(2.88 \%)$ & 2.18 (1.52 to 3.14$)$ & \\
\hline $5-6$ & $2(0.32 \%)$ & $6(0.08 \%)$ & 3.85 (0.78 to 19.14$)$ & \\
\hline Abdomen & & & & $<0.0001$ \\
\hline 0 & $552(85.98 \%)$ & $6319(92.86 \%)$ & 1 & \\
\hline 1 & $7(1.09 \%)$ & $38(0.56 \%)$ & 2.109 (0.94 to 4.74$)$ & \\
\hline 2 & 42 (6.54\%) & $222(3.26 \%)$ & 2.166 (1.57 to 3.05$)$ & \\
\hline 3 & $23(3.58 \%)$ & $141(2.07 \%)$ & 1.867 (1.19 to 2.93$)$ & \\
\hline 4 & $13(2.02 \%)$ & 69 (1.01\%) & 2.157 (1.19 to 3.93$)$ & \\
\hline 5 & $5(0.78 \%)$ & $16(0.24 \%)$ & 3.583 (1.31 to 9.81$)$ & \\
\hline Extremities & & & & $<0.0001$ \\
\hline 0 & $261(40.65 \%)$ & $1839(29.02 \%)$ & 1 & \\
\hline 1 & $63(9.81 \%)$ & 435 (6.39\%) & 1.020 (0.76 to 1.37$)$ & \\
\hline 2 & $185(28.82 \%)$ & 2973 (43.69\%) & 0.438 (0.36 to 0.53$)$ & \\
\hline $3-5$ & $133(20.72 \%)$ & $1558(22.89 \%)$ & 0.61 (0.48 to 0.75$)$ & \\
\hline 14 & & & & 0.195 \\
\hline 0 & $536(83.49 \%)$ & 5799 (85.22\%) & 1 & \\
\hline 1 & 102 (15.89\%) & $981(14.42 \%)$ & 1.125 (0.90 to 1.41$)$ & \\
\hline 2 & $4(0.62 \%)$ & $25(0.37 \%)$ & 1.731 (0.60 to 4.99$)$ & \\
\hline
\end{tabular}

BAC, blood alcohol concentration; DUI, driving under the influence.

injuries involving alcohol-intoxicated drivers are influenced less by geographic and environmental factors than by the nature of collision and time of crash. ${ }^{39}$ Our results indicate different temporal distribution (in weekday and time of day, but not in seasons) in the DUI and non-DUI groups. Most non-DUI patients visited the ER between early morning and afternoon (06:00-14:00), but DUI patients tend to search for medical aid between 22:00 and 06:00 (50.31\%). A previous study in Hong Kong indicated a similar temporal pattern in DUI using a slightly different time framework. ${ }^{40}$ This study found that most DUI events occurred between 15:00 and 23:00 (39.5\%) and between 23:00 and 07:00 (29.8\%). Consistent with our findings, a higher prevalence of DUI on weekends than on weekdays is reported in other studies. ${ }^{41}$ In addition, the significant drop in SVN/MVD ratio after the legal BAC limit was lowered indicated that the limit change had an effect on the reduction in DUI behaviour.

Although our study found that DUI events significantly decreased after the legal BAC limit was lowered, the 
increased point estimate for OR of DUI on mortality was not significant. Moreover, in DUI patients, the postlimit change mortality OR was significantly higher than prelimit change. This may be explained by the possibility that DUI drivers after the change were more addicted to alcohol and had a lower helmet use rate. Studies have shown that alcohol impairs driving ability, and that the intoxicated driver is more likely to cause fatal road traffic crashes, ${ }^{42}$ while other research has found the risk of mortality is not higher in patients with positive BAC. ${ }^{3}$ Some studies have found that serum ethanol is independently associated with increased mortality. ${ }^{43} 44$ Furthermore, some studies have proposed alcohol use can have a protective effect in trauma patients. ${ }^{345} 46$ In this study, we did not find a protective role for DUI in our analysis of the association between DUI and AIS. These findings indicated that lowering the legal BAC limit can reduce alcohol-impaired driving, ${ }^{48}$ but may be not enough to result in a significant reduction in mortality of those trauma patients. This may indicate that other preventative policies, such as taxes on alcohol, minimum legal drinking ages and administrative license revocation, should be considered. ${ }^{49}$ In fact, drivers with or without DUI had more heterogeneity in the factors that may affect injury severity. ${ }^{50}$ Bias may exist in the analysis with multivariate logistic regression for the association between the injury severity and the drivers with or without DUI, which may comprise a limitation in this study.

There are some other limitations to our study. First, the analysis was based on data from the trauma registry system of a level I regional trauma centre in southern Taiwan. These results may not be externally valid. Besides, our selected statistical methods with limited parameters may not clarify the contributing factors and outcomes of DUI crashes due to its complex interaction. ${ }^{51}$ Second, there were differences in the baseline characteristics of patients admitted after traffic crashes before and after sanction change. The differences in baseline characteristics may have confounded results and observed differences may have implied the effect of sanction change. Third, the combined use of psychoactive medication and alcohol may increase the risk of having a crash. ${ }^{52} 53$ This confounder was not controlled in our study, although this bias is random. Fourth, patients seeking medical care due to a traffic crash did not routinely receive a blood alcohol test unless they showed symptoms of being alcohol-impaired or unconsciousness. This may underestimate the effect of DUI in our analysis. Fifth, our registry system is not able to report exact time elapsed from injury to an alcohol test. However, the mean transport time for the patients transported by emergency medical service to the hospital was $18.3 \pm 7.9 \mathrm{~min}$ according to our data and $\sim 12$ min according to Taiwan government data from January 2009 to June 2009. Thus, the bias may be minimal. In addition, driver use of safety belt was not registered in the trauma database, so we could not investigate this important variable. Furthermore, our registry system did not exclude the repeated DUI patients; although these drivers may be a small group in our study subjects, they may confound our statistical results. Finally, there may exist bias in the outcome assessment with control of alcohol consumption, vehicle miles travelled and vehicles and motorcycles registered, which were lacking in the registered trauma database.

\section{CONCLUSION}

This study revealed that lowering the legal limit for BAC to $30 \mathrm{mg} / \mathrm{dL}$ significantly reduced DUI events, but failed to result in a significant reduction in traffic crash mortality. Airbag use in car crashes and helmet use in motorcycle crashes after the limit change was less in DUI patients than in non-DUI patients, with significant negative correlation.

\section{Author affiliations}

${ }^{1}$ Department of Neurosurgery, Kaohsiung Chang Gung Memorial Hospital and Chang Gung University College of Medicine, Kaohsiung, Taiwan

${ }^{2}$ Department of Anesthesiology, Kaohsiung Chang Gung Memorial Hospital and Chang Gung University College of Medicine, Kaohsiung, Taiwan

${ }^{3}$ Department of Plastic Surgery, Kaohsiung Chang Gung Memorial Hospital and Chang Gung University College of Medicine, Kaohsiung, Taiwan

Acknowledgements We thank the Biostatistics Centre at the Kaohsiung Chang Gung Memorial Hospital for their help with the statistical analysis.

Contributors Y-CT wrote the manuscript. S-CW revised the manuscript. J-FH assisted with the study design. SCHK was involved in the literature review. C-SR was responsible for the integrity of registered data. P-CC performed the statistical analyses and edited the tables. $\mathrm{H}$ - $\mathrm{YH}$ proofread the manuscript. $\mathrm{C}-\mathrm{HH}$ designed the study and contributed to the data analysis and interpretation. All authors read and approved the final manuscript.

Funding This research was supported by a grant from Chang Gung Memorial Hospital CGRPG8F0011.

Disclaimer The depiction of boundaries on the map(s) in this article do not imply the expression of any opinion whatsoever on the part of BMJ (or any member of its group) concerning the legal status of any country, territory, jurisdiction or area or of its authorities. The map(s) are provided without any warranty of any kind, either express or implied.

Competing interests None declared.

Patient consent for publication Not required.

Ethics approval This study was approved bythe institutional review boar $\mathrm{d}$ of the Kaohsiung Chang GungMemorial Hospital (reference number 201701844B0).

Provenance and peer review Not commissioned; externally peer reviewed.

Data sharing statement The datasets analysed during the current study are not publicly available due to the privacy policy but are available from the corresponding author on reasonable request.

Open access This is an open access article distributed in accordance with the Creative Commons Attribution Non Commercial (CC BY-NC 4.0) license, which permits others to distribute, remix, adapt, build upon this work non-commercially, and license their derivative works on different terms, provided the original work is properly cited, appropriate credit is given, any changes made indicated, and the use is non-commercial. See: http://creativecommons.org/licenses/by-nc/4.0/.

\section{REFERENCES}

1. World Health Organization. Global status report on road safety: World Health Organization, 2015.

2. World Health Organization. World report on road traffic injury prevention: World Health Organization, 2004.

3. Hsieh CH, Su LT, Wang YC, et al. Does alcohol intoxication protect patients from severe injury and reduce hospital mortality? The 
association of alcohol consumption with the severity of injury and survival in trauma patients. Am Surg 2013;79:1289-94.

4. Lee MH, Mello MJ, Reinert S. Emergency department charges for evaluating minimally injured alcohol-impaired drivers. Ann Emerg Med 2009;54:593-9.

5. Martin TL, Solbeck PA, Mayers DJ, et al. A review of alcohol-impaired driving: the role of blood alcohol concentration and complexity of the driving task. J Forensic Sci 2013;58:1238-50.

6. O'Keeffe T, Rhee P, Shafi S, et al. Alcohol use increases diagnostic testing, procedures, charges, and the risk of hospital admission: a population-based study of injured patients in the emergency department. Am J Surg 2013;206:16-22.

7. Blomberg RD, Peck RC, Moskowitz H, et al. The Long Beach/Fort lauderdale relative risk study. J Safety Res 2009;40:285-92.

8. Fell JC, Voas RB. The effectiveness of a 0.05 blood alcohol concentration (BAC) limit for driving in the United States. Addiction 2014;109:869-74.

9. Taylor B, Irving HM, Kanteres F, et al. The more you drink, the harder you fall: a systematic review and meta-analysis of how acute alcohol consumption and injury or collision risk increase together. Drug Alcohol Depend 2010;110:108-16.

10. Taylor B, Rehm J. The relationship between alcohol consumption and fatal motor vehicle injury: high risk at low alcohol levels. Alcohol Clin Exp Res 2012;36:1827-34.

11. Thomas FB, Babor TF. Alcohol: no ordinary commodity-a summary of the second edition. Addiction 2010;105:769-79.

12. Ministry of Interior ROCM. Statistics of police administration: Ministry of Interior ROCM, 2018.

13. Chan YS, Chen CS, Huang L, et al. Sanction changes and drunkdriving injuries/deaths in Taiwan. Accid Anal Prev 2017;107:102-9.

14. Hsieh CH, Hsu SY, Hsieh HY, et al. Differences between the sexes in motorcycle-related injuries and fatalities at a Taiwanese level I trauma center. Biomed J 2017;40:113-20.

15. Hsieh CH, Liu HT, Hsu SY, et al. Motorcycle-related hospitalizations of the elderly. Biomed J 2017;40:121-8.

16. Hsieh $\mathrm{CH}$, Chen YC, Hsu SY, et al. Defining polytrauma by abbreviated injury scale $\geq 3$ for a least two body regions is insufficient in terms of short-term outcome: a cross-sectional study at a level i trauma center. Biomed J 2018;41:321-7.

17. Voas RB, Romano E, Peck R. Validity of surrogate measures of alcohol involvement when applied to nonfatal crashes. Accid Anal Prev 2009;41:522-30.

18. Heeren T, Smith RA, Morelock S, et al. Surrogate measures of alcohol involvement in fatal crashes: are conventional indicators adequate? J Safety Res 1985;16:127-34.

19. Maxwell JC, Freeman J. Gender differences in DUI offenders in treatment in Texas. Traffic Inj Prev 2007;8:353-60.

20. Tang CE, Liu HT, Kuo PJ, et al. Impact of sexual dimorphism on trauma patterns and clinical outcomes of patients with a highrisk score of the osteoporosis self-assessment tool for asians: a propensity score-matched analysis. Int J Environ Res Public Health 2018;15:418.

21. Apidechkul $\mathrm{T}$, Laingoen $\mathrm{O}$, Suwannaporn $\mathrm{S}$, et al. Factors influencing motorcycle accidents among hill tribe youths in Chiang Rai, Thailand. Thai J Health Res 2017;31:473-80.

22. Mbanjumucyo G, George N, Kearney A, et al. Epidemiology of injuries and outcomes among trauma patients receiving prehospital care at a tertiary teaching hospital in Kigali, Rwanda. Afr J Emerg Med 2016;6:191-7.

23. Eagon PK. Alcoholic liver injury: influence of gender and hormones. World J Gastroenterol 2010;16:1377

24. Hommer DW. Male and female sensitivity to alcohol-induced brain damage. Alcohol Res Health 2003;27:181-5.

25. Bradley KA, Badrinath S, Bush $\mathrm{K}$, et al. Medical risks for women who drink alcohol. J Gen Intern Med 1998;13:627-39.

26. Nolen-Hoeksema S. Gender differences in risk factors and consequences for alcohol use and problems. Clin Psychol Rev 2004:24:981-1010.

27. Nolen-Hoeksema S, Hilt L. Possible contributors to the gender differences in alcohol use and problems. J Gen Psychol 2006;133:357-74.

28. Horswill MS, Coster ME. The effect of vehicle characteristics on drivers' risk-taking behaviour. Ergonomics 2002;45:85-104.
29. Buckley L, Bingham CR, Flannagan CA, et al. Observation of motorcycle helmet use rates in Michigan after partial repeal of the universal motorcycle helmet law. Accid Anal Prev 2016;95:178-86.

30. Kuo SCH, Kuo PJ, Rau CS, et al. The protective effect of helmet use in motorcycle and bicycle accidents: a propensity score-matched study based on a trauma registry system. BMC Public Health 2017; $17: 639$

31. Lin KC, Peng SH, Kuo PJ, et al. Patterns associated with adult mandibular fractures in Southern Taiwan-A cross-sectional retrospective study. Int J Environ Res Public Health 2017;14:821.

32. Heydari ST, Vossoughi M, Akbarzadeh A, et al. Prevalence and risk factors of alcohol and substance abuse among motorcycle drivers in Fars province, Iran. Chin J Traumatol 2016;19:79-84.

33. Maistros A, Schneider WH, Savolainen PT. A comparison of contributing factors between alcohol related single vehicle motorcycle and car crashes. J Safety Res 2014;49:129.e1-35.

34. Hingson R, Heeren T, Winter M. Effects of Maine's $0.05 \%$ legal blood alcohol level for drivers with DWI convictions. Public Health Rep 1998;113:440-6.

35. Homel R. Drink-driving law enforcement and the legal blood alcohol limit in New South Wales. Accid Anal Prev 1994;26:147-55.

36. Blais É, Bellavance $F$, Marcil A, et al. Effects of introducing an administrative $0.05 \%$ blood alcohol concentration limit on law enforcement patterns and alcohol-related collisions in Canada. Accid Anal Prev 2015;82:101-11.

37. Fell JC, Scherer M. Estimation of the potential effectiveness of lowering the blood alcohol concentration (bac) limit for driving from 0.08 to 0.05 grams per deciliter in the United States. Alcohol Clin Exp Res 2017:41:2128-39.

38. Chen $\mathrm{H}$, Chen $\mathrm{Q}$, Chen $\mathrm{L}$, et al. Analysis of risk factors affecting driver injury and crash injury with drivers under the influence of alcohol (DUI) and non-DUI. Traffic Inj Prev 2016;17:796-802.

39. Velmurugan S, Padma S, Madhu E, et al. A study of factors influencing the severity of road crashes involving drunk drivers and non drunk drivers. Research in Transportation Economics 2013;38:78-83.

40. Li YC, Sze NN, Wong SC. Spatial-temporal analysis of drink-driving patterns in Hong Kong. Accid Anal Prev 2013;59:415-24.

41. Damsere-Derry J, Palk G, King M. Prevalence of alcohol-impaired driving and riding in northern Ghana. Traffic Inj Prev 2016;17:226-32.

42. Impinen $A$, Mäkelä $P$, Karjalainen $\mathrm{K}$, et al. High mortality among people suspected of drunk-driving. An 18-year register-based followup. Drug Alcohol Depend 2010;110:80-4

43. Pories SE, Gamelli RL, Vacek P, et al. Intoxication and injury. $J$ Trauma 1992;32:60-4

44. Luna GK, Maier RV, Sowder L, et al. The influence of ethanol intoxication on outcome of injured motorcyclists. J Trauma 1984;24:695-700.

45. Cherry RA, Nichols PA, Snavely TM, et al. Resource utilization and outcomes of intoxicated drivers. J Trauma Manag Outcomes 2010;4:9.

46. Plurad D, Demetriades D, Gruzinski G, et al. Motor vehicle crashes: the association of alcohol consumption with the type and severity of injuries and outcomes. J Emerg Med 2010;38:12-17.

47. Bachmann M, Dixon AL. DWI Sentencing in the United States: toward promising punishment alternatives in Texas. Int J Crim Just Sci 2014;9:181-91

48. Yao J, Johnson MB, Beck KH. Predicting DUI decisions in different legal environments: investigating deterrence with a conjoint experiment. Traffic Inj Prev 2014;15:213-21.

49. Chang K, Wu CC, Ying YH. The effectiveness of alcohol control policies on alcohol-related traffic fatalities in the United States. Accid Anal Prev 2012;45:406-15.

50. Behnood A, Mannering FL. The effects of drug and alcohol consumption on driver injury severities in single-vehicle crashes. Traffic Inj Prev 2017;18:456-62.

51. Behnood A, Roshandeh AM, Mannering FL. Latent class analysis of the effects of age, gender, and alcohol consumption on driver-injury severities. Anal Methods Accid Res 2014;3-4:56-91.

52. Bogstrand ST, Gjerde H, Normann PT, et al. Alcohol, psychoactive substances and non-fatal road traffic accidents-a case-control study. BMC Public Health 2012;12:734.

53. Ricci G, Majori S, Mantovani W, et al. Prevalence of alcohol and drugs in urine of patients involved in road accidents. J Prev Med Hyg 2008;49:89-95. 